\title{
Evaluation of Helicobacter pylori Eradication Therapy in Dyspeptic Patients in a Teaching Hospital
}

\author{
Ahmed A. Abusham ${ }^{1^{*}}$ and Abdul Wahab H. Mohammed ${ }^{2}$ \\ ${ }^{1}$ School of Pharmacy, College of pharmacy and Nursing, University of Nizwa, Oman \\ ${ }^{2}$ Sudan National Research Centre, Sudan
}

\section{Abstract}

Objectives: The main purpose of this study was to evaluate $H$ pylori eradication therapy in a tertiary care teaching hospital.

Method: In this retrospective study, the eradication therapy for 83 patients was evaluated. Data was collected over six-month period. All prescriptions identified as for $H$ pylori eradication during that period were considered eligible for the study. Patients' medical records were also reviewed. Collection of data was done using a predesigned data collection form. Analysis was performed using Statistical Package (STATA v12.0).

Results: Regimens considered inappropriate comprised $41 \%$ of all prescribed regimens. Eighty percent of the inappropriate regimens consist of one or no antibiotic. "H pylori associated chronic gastritis" represents $88 \%$ of indications for eradication therapy. Abdominal pain and headache appeared to be the most commonly encountered adverse drug reactions (ADRs) in patients prescribed eradication therapy. Seventy six percent of the interviewed patients reported that they were not counseled about the potential ADRs of the prescribed medications.

Conclusion: A number of inappropriate therapies for eradication of $H$ pylori were observed. Patients were not fully aware of potential adverse drug reactions, which compromise patient compliance. Prescribing for $\mathrm{H}$ pylori eradication could be improved through well-defined guidelines. Patients should be counselled on the negative consequences of poor adherence to eradication therapy.

\section{Publication History:}

Received: January 28, 2016

Accepted: May 15, 2016

Published: May 17, 2016

\section{Keywords:}

Helicobacter pylori, Eradication therapy, Gastritis, Dyspepsia

\section{Introduction}

The main objective of the study was to evaluate Helicobacter pylori ( $H$ pylori) eradication therapy considering eradication regimen, invasive and non-invasive tests performed, and commonly encountered adverse events during eradication therapy in Sultan Qaboos University Hospital (SQUH), a tertiary care teaching hospital.

Helicobacter pylori - formerly called Campylobacter pylori - is a gram-negative rod, spiral-shaped organism with multiple, polar, flagella, it is adapted to life in the stomach. It was first cultured and suggested as a pathogenic factor in peptic ulcer disease by Robin Warren and his colleague Barry Marshall in the early 1980's [1] when they reported the causative evidence linking $H$ pylori to ulceration, which was compelling enough to regard duodenal and gastric ulcers as infectious diseases in the majority of cases. Eradication of $H$ pylori is strongly linked to ulcer healing and prevention of ulcer recurrence [23].

This bacterium survive a highly acidic environment by producing urease, which breaks down urea into ammonia and carbon dioxide and allows the organism to control the $\mathrm{pH}$ in its local environment in the stomach by neutralizing the hydrogen ions in gastric acid. It grows in vitro between $\mathrm{pH} 6$ and 8.5 and survives between $\mathrm{pH} 4$ and 8.5 in the absence of urea $[4,5]$. This may explain the role of proton pump inhibitor being given concomitantly with antibiotics.

Functional differences between strains of $H$ pylori exist based on their genomic pattern. Virulence and tissue damage vacuolating cytotoxin gene (VacA), that causes gastric tissue damage, and cytotoxin-associated gene (CagA) which is not cytotoxic but is antigenic and can be detected serologically $[6,7]$.

Epidemiologic studies have established that more than 50\% of the world's population is colonized with $H$ pylori [4]. According to the
International Agency for Research on Cancer, gastric cancer affects 900,000 people annually, the agency classified $H$ pylori as a class 1 carcinogen $[8,9]$.

The American National Institute of Health (NIH) Consensus Panel recommends all patients with duodenal or gastric ulcers and who are $H$ pylori positive should be treated [10]. The European Helicobacter pylori Study Group recognized that many patients presenting to the doctor with symptoms of dyspepsia could be diagnosed and treated in primary care [11].

Acid inhibition combined with antibiotic treatment is effective in eradicating $H$ pylori bacteria. Veldhuyzen et al., [12] compared antimicrobial treatments with conventional ulcer therapy (proton pump inhibitors (PPI) and histamine 2 receptor antagonists (H2RA)) and found that use of antibiotics increases ulcer healing rates from 78 per cent to 93 per cent, decreases first year ulcer recurrence rates from 66 per cent to 9 per cent and eliminates the need for long-term maintenance once the ulcer has healed.

Various regimens of combined anti-secretary agents plus antibiotics have been proposed and tested, but no therapy is 100 per cent effective and no regimen is considered ideal. Many antibiotics show good

"Corresponding Author: Dr. Ahmed A. Abusham, School of Pharmacy, College of pharmacy and Nursing, University of Nizwa, Birkat Al Mawz, Oman; E-mail: abusham@unizwa.edu.om

Citation: Abusham AA, Mohammed AH (2016) Evaluation of Helicobacter pylori Eradication Therapy in Dyspeptic Patients in a Teaching Hospital. Int J Clin Pharmacol Pharmacother 1: 104. doi: https://doi.org/10.15344/2456$3501 / 2016 / 104$

Copyright: (c) 2016 Abusham et al. This is an open-access article distributed under the terms of the Creative Commons Attribution License, which permits unrestricted use, distribution, and reproduction in any medium, provided the original author and source are credited. 
in vitro activity against $H$ pylori but single antibiotics are usually ineffective in clinical practice and may magnify the problem of drug resistance. This is because of the acidic environment which decreases antibiotic activity, and the protective nature of the gastric mucus in which the bacterium survives [13].

The current standard of $H$ pylori eradication treatment, confirmed by studies presented at the Lisbon workshop of the European meeting on $H$ pylori [14] is seven days of one of three PPI-based triple therapies. These combine a PPI with two antibiotics chosen from clarithromycin, Amoxicillin and metronidazole.

Recently, the sequential triple therapies showed improve in eradication rates, especially with clarithromycin resistant strains. No differences in the prevalence of antimicrobial resistance or incidence of adverse events were observed when comparing sequential to traditional therapy $[15,16]$. Also, Probiotics, which are live nonpathogenic bacteria, were found to reduce side effects of standard $H$. pylori treatments as adjunct therapy [17].

Tested $H$ pylori eradication therapies included 7-day, 10-day, and 14-day treatment courses. The duration of therapy is controversial, as shorter periods may enhance compliance but with low eradication rate, on the other hand longer treatment periods favour higher eradication rates and are less likely to be associated with antimicrobial resistance but compliance remains an issue $[18,13]$.

The prevalence of pre-treatment antibiotic resistance varies, but as been estimated at $2-3 \%$ for clarithromycin and around $30 \%$ for metronidazole [19]. There is particular concern over the emergence of strains resistant to metronidazole [20]. Previous use of metronidazole, particularly for gynaecological infections, may be an important contributory factor $[21,22]$.

$H$ pylori infection is considered eradicated if the organism cannot be detected one month after therapy is stopped. Because urea breath testing (UBT) depends on measuring the presence of urease activity, it is important that suppression of urease activity by medication does not occur at the time of testing, resulting in a false negative result. H2RAs and PPIs are known to produce false-negative urease-based test results [23].

\section{Methods}

\section{Study population and sample selection}

Study sample was drawn from SQUH a 500-bed governmentfunded tertiary care teaching hospital. All patients aged 18 and above and prescribed $H$ pylori eradication therapy were eligible for this study.

\section{Sample size}

All patients who were prescribed $H$ pylori eradication therapy during a period of 6 months $(n=87)$ were examined. Four patients were excluded because of incomplete information. The rest $(n=83)$ were 64 from surgery and 19 from gastroenterology units.

\section{Data collection procedure}

Data from all prescriptions identified as for $H$ pylori eradication therapy were collected using a predesigned data collection form based on the literature review and expert panel (a clinical pharmacist, a physician and a statistician). Items in the data collection form include patient demographics, endoscopy and diagnosis, regimen structure including does, frequency, duration and maintenance therapy. Patients were interviewed, through telephone calls - after getting their permission - to retrieve the commonly encountered adverse events during $H$ pylori eradication therapy.

To complete the data collection, patients' clinical records and relevant laboratory tests were reviewed. Pharmacist intervention records were also reviewed to see if changes were made to the prescribed regimens.

\section{Data analysis}

Data analyzed included invasive and non-invasive tests done before and/or after eradication therapy, eradication therapy regimen used adverse events during therapy and demographic characteristics of patients. Eradication therapy regimen was considered inappropriate if the dose, frequency or duration of any of the drugs in a regimen or if the regimen structure was different from the standard eradication therapies based on the British National Formulary (BNF) [24] as per SQUH guidelines. The main outcome of the study was eradication regimen, depending on medications per regimen, dose and frequency of each medication and duration of therapy. Other parameters like endoscopy, non-invasive testing and commonly encountered adverse events during eradication therapy were analyzed based on clinical merit and prior research.

The outcome was compared to the existing European H pylori Study Group and the American College of Gastroenterology guidelines. Eradication therapy regimens were compared to the standard regimens as per the British National Formulary (BNF).

The study was approved by the Research and Ethics committee of the College of medicine \& Health Sciences at the Sultan Qaboos University in Muscat, Oman.

[Research proposal MREC 119, Evaluation of H. pylori Eradication Therapy in Dyspeptic Patients in SQUH]

Statistical analyses were conducted using STATA version 12.0 (Stata Corporation, 2007; College Station, TX, USA).

\section{Results}

Demographic characteristics of 83 patients $(n=83)$ who were prescribed $H$ pylori eradication therapy during a six-month period are shown in Table 1 . Most of patients (60.2\%) were females. Patients' age range was 18 - 70 years and most of them (74.7\%) were in the age category of $30-59$ years. The mean age is 43.6 years. Most of the patients $(77.1 \%)$ were seen and treated by surgeons.

Seventy Eight (94\%) of the patients involved in the study were endoscoped. Of those, only four (4.8\%) underwent endoscopy before and after treatment. Five patients $(6 \%)$ were treated empirically with eradication therapy without being tested.

Most of the patient patients $(88 \%)$ were diagnosed as 'chronic active gastritis' and were $H$ pylori positive. Five patients (6\%) of those who underwent endoscopy were $H$ pylori negative. Four patients (4.8\%) were endoscopically proven to have duodenal ulcer and concurrent $H$ Pylori infection. Only one patient was reported to have $H$ pylori associated gastric ulcer. He was endoscoped before and after eradication therapy. Table 2 shows clinical characteristics of patients. 
Citation: Abusham AA, Mohammed AH (2016) Evaluation of Helicobacter pylori Eradication Therapy in Dyspeptic Patients in a Teaching Hospital. Int J Clin Pharmacol Pharmacother 1: 104. doi: https://doi.org/10.15344/2456-3501/2016/104

Page 3 of 6

\begin{tabular}{|l|l|l|l|}
\hline \multicolumn{2}{|l|}{ Characteristics } & $\mathrm{n}$ & $\%$ \\
\hline Gender & Male & 33 & 39.8 \\
\hline & Female & 50 & 60.2 \\
\hline Age & $<30$ years & 15 & 18.1 \\
\hline & $30-44$ years & 27 & 32.5 \\
\hline & $45-60$ years & 35 & 42.2 \\
\hline Clinic & $>60$ years & 6 & 7.20 \\
\hline & Gastroenterology & 19 & 22.9 \\
\hline Location & Surgery & 64 & 77.1 \\
\hline & Outpatients & 78 & 94.0 \\
\hline
\end{tabular}

Table 1: Demographic Characteristics of Patients $(\mathrm{N}=83)$.

\begin{tabular}{|c|c|c|c|}
\hline \multicolumn{2}{|c|}{ Characteristics } & \multirow{2}{*}{$\begin{array}{l}\mathrm{n} \\
78\end{array}$} & \multirow{2}{*}{$\begin{array}{l}\% \\
94\end{array}$} \\
\hline Endoscopy & done & & \\
\hline & not done & 5 & 6 \\
\hline & before treatment & 74 & 89.2 \\
\hline & before and after treatment & 4 & 4.8 \\
\hline \multirow[t]{5}{*}{ Diagnosis } & H pylori positive & 73 & 88 \\
\hline & H pylori negative & 5 & 6 \\
\hline & gastritis & 73 & 88 \\
\hline & duodenal ulcer & 4 & 4.8 \\
\hline & gastric ulcer & 1 & 1.2 \\
\hline
\end{tabular}

Table 2: Characteristics of endoscopy and diagnosis.

Eradication therapy was considered inappropriate if its structure was different from that of the standard regimens and/or if the dose, frequency or duration of any of the drugs in that regimen was incorrect as per the BNF [24] (Table 3). Thirty-four (41\%) of the prescribed regimens were inappropriate. Further analysis of inappropriate regimens revealed incorrect doses, frequencies and duration in $28.6 \%, 26.5 \%$, and $32.7 \%$ of the prescribed medications respectively (Figure 1). Analysis of inappropriate regimens also revealed that $79.4 \%$ of the regiments contained one or no antibiotic. Commonly prescribed regimen $(24.1 \%)$ was the one consists of

"Omeprazole $20 \mathrm{mg}$ twice daily + Clarithromycin $500 \mathrm{mg}$ twice daily + Amoxicillin $1 \mathrm{~g}$ twice daily" (Table 4). Forty-eight patients (57.8\%) were prescribed maintenance therapy, mainly ranitidine $(32.5 \%)$ or omeprazole $(25.3 \%)$ as seen in Table 5.

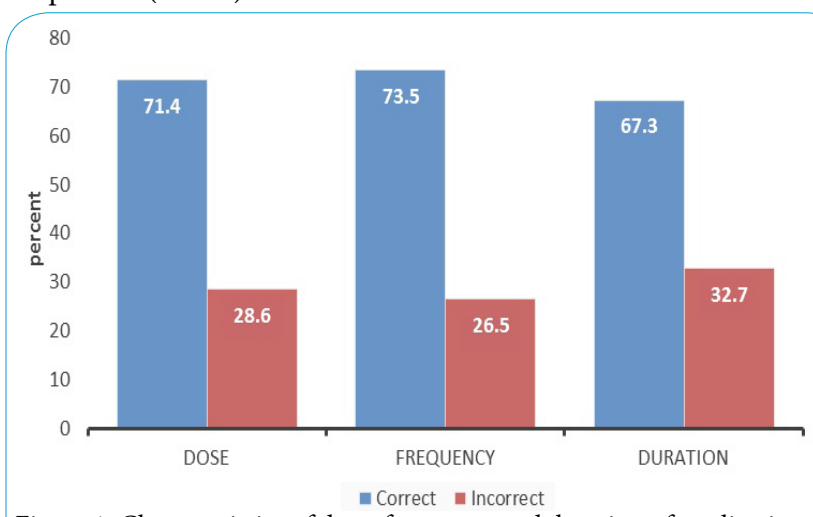

Figure 1: Characteristics of dose, frequency and duration of eradication therapy.

\begin{tabular}{|l|l|l|}
\hline Regimen & $\mathrm{n}$ & $(\%)$ \\
\hline $\begin{array}{l}\text { Omeprazole 20mg bd + Clarithromycin } 500 \mathrm{mg} \text { bd + } \\
\text { Amoxicillin 1 g bd. }\end{array}$ & 20 & 24.1 \\
\hline $\begin{array}{l}\text { Omeprazole } 20 \mathrm{mg} \text { bd + Clarithromycin } 500 \mathrm{mg} \text { bd + } \\
\text { Metronidazole } 400 \mathrm{mg} \text { bd. }\end{array}$ & 14 & 16.9 \\
\hline $\begin{array}{l}\text { Ranitidine } 150 \mathrm{mg} \text { bd + Clarithromycin } 500 \mathrm{mg} \text { bd + } \\
\text { Metronidazole } 400 \mathrm{mg} \text { bd. }\end{array}$ & 7 & 8.4 \\
\hline $\begin{array}{l}\text { Ranitidine } 150 \mathrm{mg} \text { bd + Amoxicillin } 1 \mathrm{~g} \text { bd } \\
+ \text { Metronidazole } 400 \mathrm{mg} \text { bd. }\end{array}$ & 3 & 3.6 \\
\hline $\begin{array}{l}\text { Ranitidine } 150 \mathrm{mg} \text { bd + Clarithromycin } 500 \mathrm{mg} \text { bd + } \\
\text { Amoxicillin } 1 \mathrm{~g} \text { bd. }\end{array}$ & 3 & 3.6 \\
\hline $\begin{array}{l}\text { Omeprazole } 20 \mathrm{mg} \text { bd + Amoxicillin } 500 \mathrm{mg} \text { bd + } \\
\text { Metronidazole } 400 \mathrm{mg} \text { bd. }\end{array}$ & 2 & 2.4 \\
\hline Others & 34 & 41 \\
\hline
\end{tabular}

For logistic reasons, only twenty-one patients (25.3\%) were interviewed through telephone calls. The commonly encountered adverse event reported by interviewed patients included abdominal pain $(37.5 \%)$, headache $(34.4 \%)$, nausea $(15.6 \%)$, unpleasant or

\begin{tabular}{|c|c|c|c|}
\hline \multirow[b]{2}{*}{ Acid suppressant } & \multicolumn{3}{|l|}{ Antibacterial } \\
\hline & Amoxicillin & Clarithromycin & Metronidazole \\
\hline \multirow[t]{2}{*}{ Esomeprazole $20 \mathrm{mg}$ twice daily } & $1 \mathrm{~g}$ twice daily & 500 mg twice daily & - \\
\hline & - & $250 \mathrm{mg}$ twice daily & $400 \mathrm{mg}$ twice daily \\
\hline \multirow[t]{3}{*}{ Lansoprazole $30 \mathrm{mg}$ twice daily } & $1 \mathrm{~g}$ twice daily & 500 mg twice daily & - \\
\hline & $1 \mathrm{~g}$ twice daily & - & $400 \mathrm{mg}$ twice daily \\
\hline & - & 250 mg twice daily & 400 mg twice daily \\
\hline \multirow{3}{*}{$\begin{array}{l}\text { Omeprazole } 20 \text { mg twice daily OR Ranitidine } 150 \\
\text { mg twice daily }\end{array}$} & $1 \mathrm{~g}$ twice daily & $500 \mathrm{mg}$ twice daily & - \\
\hline & $500 \mathrm{mg} 3$ times daily & - & $400 \mathrm{mg} 3$ times daily \\
\hline & - & 250 mg twice daily & 400 mg twice daily \\
\hline \multirow{2}{*}{$\begin{array}{l}\text { Pantoprazole } \\
40 \text { mg twice daily }\end{array}$} & $1 \mathrm{~g}$ twice daily & 500 mg twice daily & - \\
\hline & - & $250 \mathrm{mg}$ twice daily & 400 mg twice daily \\
\hline \multirow{2}{*}{$\begin{array}{l}\text { Rabeprazole } \\
20 \text { mg twice daily }\end{array}$} & $1 \mathrm{~g}$ twice daily & 500 mg twice daily & - \\
\hline & - & $250 \mathrm{mg}$ twice daily & $400 \mathrm{mg}$ twice daily \\
\hline
\end{tabular}

Table 3: Recommended regimens for Helicobacter pylori eradication in adults (BNF, 2012). 
Citation: Abusham AA, Mohammed AH (2016) Evaluation of Helicobacter pylori Eradication Therapy in Dyspeptic Patients in a Teaching Hospital. Int J Clin Pharmacol Pharmacother 1: 104. doi: https://doi.org/10.15344/2456-3501/2016/104

Page 4 of 6

metallic taste (6.3\%) and diarrhoea (3.1\%). Figure 2 shows graphical presentation of adverse drug event. Only five (23.8\%) of the interviewed patients reported that the pharmacist did discuss with them the potential adverse drug reactions and/or pointed out the importance of complying with the prescribed eradication therapy.

\begin{tabular}{|l|l|l|l|}
\hline Characteristic & $\mathrm{n}$ & $\%$ & \\
\hline Regimen structure & Correct & 49 & 59.0 \\
\hline & Incorrect & 34 & 41.0 \\
\hline Maintenance therapy & Omeprazole & 21 & 25.3 \\
\hline & Ranitidine & 27 & 32.5 \\
\hline & None & 35 & 42.2 \\
\hline
\end{tabular}

Table 5: Characteristics of regimen structure and maintenance therapy.

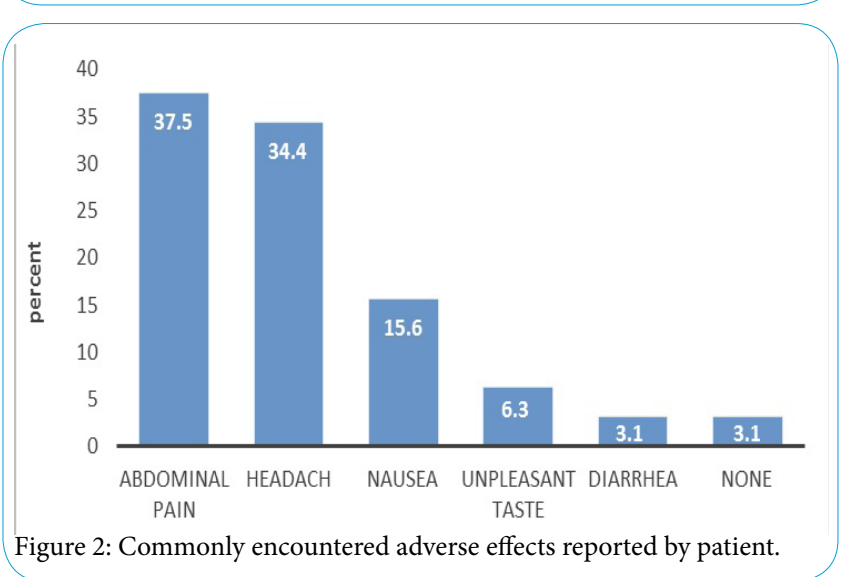

\section{Discussion}

Evidence proved that eradication of $H$ pylori with combined antimicrobial and conventional ulcer therapy (H2RAs or PPIs), while considering patient's factors, is strongly linked to ulcer healing and prevention of ulcer recurrence [3].

Results of this study revealed that $42.2 \%$ of patients were in the age category of 65-59, and this with other symptoms was considered as alarming features. The American Society for Gastroenterology [25] highly recommended endoscopy for patients with alarming features such as the onset of symptoms after 45 years of age, blood loss, weight loss, anaemia, anorexia, and dysphagia.

Most of the patients (94\%) in this study were endoscoped before treatment. That was consistent with many guidelines as infection of $H$ pylori can be diagnosed by endoscopic biopsy of the gastric mucosa or by non-invasive methods like Urea Breath Test (UBT) $[11,26,27]$.

Of the eighty-three studied patients, five were offered $H$ pylori eradication therapy despite the negative endoscopy result. This is obviously inappropriate as other causes must be excluded, or if necessary, tests may be repeated to confirm the absence of $H$ pylori. Inappropriate overprescribing of antibiotics would add further to the serious problem of antibiotics resistance among $H$ pylori, and among the normal flora.

According to histopathology reports, $88 \%$ of indications for eradication therapy were ' $H$ pylori associated chronic gastritis'. The eradication therapy that considered as inappropriate comprised $41 \%$ of the prescribed regimens and almost $80 \%$ of these inappropriate regiments contained one or no antibiotic. In general, the selection of appropriate regimen should take into consideration several issues like eradication rate, complexity of regimen, cost, and resistance rate in the population [25]

A standard eradication therapy regimen should comprise a PPI or H2RA and two antibiotics of the following: clarithromycin, amoxicillin and metronidazole [24]. In MACH2 study [28], they found that treatment with omeprazole-clarithromycin-metronidazole or omeprazole-clarithromycin-amoxicillin achieved eradication in $95 \%$ and $96 \%$ of cases respectively, compared with $79 \%$ when omeprazole- amoxicillin-metronidazole regimen was used.

With clarithromycin resistant strains, sequential triple therapy may improve eradication rates. The 10 -day regimen involves a PPI (twice daily) and amoxicillin ( $1 \mathrm{~g}$ twice daily) for five days, followed by a PPI (twice daily) plus clarithromycin (500 $\mathrm{mg}$ twice daily) and tinidazole (500 mg twice daily) for five days. In one trial, eradication was significantly greater with the sequential regimen than with triple therapy treatment (89 versus 77 percent) [29].

The most prescribed antisecretory drug in this study was omeprazole (43.4\%) followed by ranitidine (15.6\%), (Table 3). Recent guidelines for $H$ pylori eradication favours PPI over H2RA. Non-availability can influence regimen structure and efficacy of treatment. For example, sometime during this study, prescribers were forced to prescribe ranitidine because omeprazole was not available in our pharmacy.

The synergism observed here is the antisecretory-induced $\mathrm{pH}$ dependent increase in the antibiotic sensitivity. Because metronidazole does not depend on cell division in its activity, no such synergism is expected when using PPI plus metronidazole. Furthermore, an antisecretory like PPl markedly inhibits gastric juice volume, thus increasing the concentration of antimicrobials in gastric juice $[4,5]$.

Further analysis of inappropriate regimens showed that $28.6 \%$ of doses, $26.5 \%$ of frequencies and $32.7 \%$ of durations were incorrect. Prescribed doses of Amoxicillin and metronidazole were ranging between $250 \mathrm{mg}$ and $500 \mathrm{mg} 8$ hourly for a duration of 5-14 days. Clarithromycin was mostly prescribed as $250 \mathrm{mg} 6$ hourly for 5-14 days. The PPI was commonly prescribed as $20 \mathrm{mg}$ twice daily for up to 30 days. The optimum dose of a macrolide in eradication therapy is still debatable. In a meta-analysis by Huang et al [30]., analysing 26 treatments of one week triple therapies with PPI-clarithromycinmetronidazole, they found that $500 \mathrm{mg}$ of clarithromycin twice a day resulted in a significantly higher eradication rate (90\%) than $250 \mathrm{mg}$ twice daily (82\%). The combination of PPI-amoxicillin-metronidazole was found less effective than regimens containing a macrolide.

In this study, results revealed $32.7 \%$ of prescribed durations as inappropriate in particular with PPI duration which was ranging between 4-8 weeks. As per The European $H$ pylori Study Group, it is not necessary to continue the treatment with PPI plus two antibiotics, for more than two weeks unless there is a complicated ulcer. That could be followed by two to four weeks maintenance therapy with PPI alone [11].

In our hospital. H pylori Resistance to metronidazole reported to be more than $40 \%$. Resistance to antibiotics is considered to be a major cause of failure in the treatment of bacterial infections in general and $H$ pylori infection in particular. When metronidazole-resistant strain of $H$ pylori is present, the effectiveness of eradication therapy can 
Citation: Abusham AA, Mohammed AH (2016) Evaluation of Helicobacter pylori Eradication Therapy in Dyspeptic Patients in a Teaching Hospital. Int J Clin Pharmacol Pharmacother 1: 104. doi: https://doi.org/10.15344/2456-3501/2016/104

Page 5 of 6

drop to $60 \%$. This is more likely in patients who previously treated with metronidazole $[13,20]$.

Although our local formulary covers all strengths of antibiotics; during this study, amoxicillin was available only as $250 \mathrm{mg}$ capsules (the required daily dose is $1 \mathrm{~g} 12$ hourly) and clarithromycin as 250 $\mathrm{mg}$ capsules (the required daily dose is $500 \mathrm{mg} 12$ hourly). This means that the patient needs to take more than 12 tablets/ capsules per day. Many patients find it difficult to take this amount of tablets/capsules on daily basis. Such issues directly affect compliance and thus the outcome of eradication therapy [13].

This non-availability/shortage problem could be attributed to the location of Oman being far from our main sources of drug supply (UK, USA), but the element of stock control deficiencies cannot be excluded and it could be the reason behind such interruption. Drug shortages are expected to be temporary or involve only a specific strength that has a substitute.

Because of logistic reasons, only a small sample of patients was interviewed to identify the common adverse drug reactions (ADRs) encountered by patients while on eradication therapy. Abdominal pain (37.5\%) appeared to be the most common ADR in particular in those who used metronidazole. Other common ADRs included headache (34.4\%) and nausea (15.6\%). Side effects are reported in up to 50 percent of patients taking one of the triple/quadruple therapy regimens and may stop treatment due to these side effects [31].

Only five $(23.8 \%)$ of the interviewed patients reported that the pharmacist did discuss with them the potential adverse drug reactions and/or pointed out the importance of complying with the prescribed therapy. According to Graham et al. [32] eradication with triple therapy fell from $96 \%$ in patients who took more than $60 \%$ of their medication to $69 \%$ in those who took less than $60 \%$ of their medication. Furthermore, eradication success was $80 \%$ in patients who were compliant with medication compared to $54 \%$ in those who were not compliant [13].

\section{Limitations of Study}

Sample size is relatively small and only few patients (25.3\%) were interviewed to identify the common ADRs of medications and extent of counselling on eradication therapy.

\section{Conclusion and Recommendations}

Prescribing pattern for $H$ pylori eradication therapy including regimen structure, doses, frequencies and duration of treatment was evaluated. Significant inappropriate prescribing for treatment and/or maintenance therapy was observed. Furthermore, patients were not fully aware of adverse drug reactions of eradication therapy.

Emphasis should be placed on guidelines as well as counselling to help patients understand the negative consequences of poor adherence to eradication therapy.

\section{Ethical Approval}

I would like to add that this study was approved by the Research and Ethics committee of the College of medicine \& Health Sciences at the Sultan Qaboos University in Muscat, Oman:

[Research proposal MREC 119, Evaluation of H. pylori Eradication Therapy in Dyspeptic Patients in SQUH].

\section{Competing Interests}

The author(s) declare that they have no competing interests.

\section{References}

1. Marshall BJ, Warren JR (1984) Unidentified curved bacilli in the stomach of patients with gastritis and peptic ulceration. Lancet 1: 1311-1315.

2. Chey WD, Wong BC; Practice Parameters Committee of the American College of Gastroenterology (2007) American College of Gastroenterology guideline on the management of Helicobacter pylori infection. Am J Gastroenterol 102: 1808-1825.

3. Malfertheiner P, Mégraud F, O'Morain C, Hungin AP, Jones R, et al. (2002) Current concepts in the management of Helicobacter pylori infection--the Maastricht 2-2000 Consensus Report. Aliment Pharmacol Ther 16: 167180.

4. Amieva MR, El-Omar EM (2008) Host-bacterial interactions in Helicobacter pylori infection. Gastroenterology 134: 306-323.

5. Malfertheiner P, Megraud F, O'Morain C, Bazzoli F, El-Omar E, et al. (2007) Current concepts in the management of Helicobacter pylori infection: the Maastricht III Consensus Report. Gut 56: 772-781.

6. Basso D, Zambon CF, Letley DP, Stranges A, Marchet A, et al. (2008) Clinical relevance of Helicobacter pylori cagA and vacA gene polymorphisms. Gastroenterology 135: 91-99.

7. Tombola F, Morbiato L, Del Giudice G, Rappuoli R, Zoratti M, et al. (2001) The Helicobacter pylori VacA toxin is a urea permease that promotes urea diffusion across epithelia. J Clin Invest 108: 929-937.

8. Jemal A, Bray F, Center MM, Ferlay J, Ward E, et al. (2011) Global cancer statistics. CA Cancer J Clin 61: 69-90.

9. Levi F, Lucchini F, Negri E, Zatonski W, Boyle P, et al. (2004) Trends in cancer mortality in the European Union and accession countries, 19802000. Ann Oncol 15: 1425-1431.

10. NIH Consensus Conference. Helicobacter pylori in peptic ulcer disease (1994) NIH Consensus Development Panel on Helicobacter pylori in Peptic Ulcer Disease. JAMA 272: 65.

11. Malfertheiner P, Megraud F, O'Morain CA, Atherton J, Axon AT, et al. (2012) Management of Helicobacter pylori infection--the Maastricht IV/ Florence Consensus Report. Gut 61: 646-664.

12. Veldhuyzen van Zanten SJ, Sherman PM (1994) Indications for treatment of Helicobacter pylori infection: a systematic overview. CMAJ 150: 189-198.

13. Fischbach LA, Goodman KJ, Feldman M, Aragaki C (2002) Sources of variation of Helicobacter pylori treatment success in adults worldwide: a meta-analysis. Int J Epidemiol 31: 128-139.

14. Peitz U, Menegatti M, Vaira D, Malfertheiner P (1998) The European meeting on Helicobacter pylori: therapeutic news from Lisbon. Gut 43 Suppl 1: S66-69.

15. Romano M, Cuomo A, Gravina AG, Miranda A, lovene MR, et al. (2010) Empirical levofloxacin-containing versus clarithromycin-containing sequential therapy for Helicobacter pylori eradication: a randomised trial. Gut 59: 1465-1470.

16. Zullo A, De Francesco V, Hassan C, Morini S, Vaira D (2007) The sequential therapy regimen for Helicobacter pylori eradication: a pooled-data analysis. Gut 56: 1353-1357.

17. Song MJ, Park DI, Park JH, Kim HJ, Cho YK, et al. (2010) The effect of probiotics and mucoprotective agents on PPI-based triple therapy for eradication of Helicobacter pylori. Helicobacter 15: 206-213.

18. Vakil N (2005) Helicobacter pylori: factors affecting eradication and recurrence. Am J Gastroenterol 100: 2393-2394.

19. Mégraud F, Lehours $P(2007)$ Helicobacter pylori detection and antimicrobial susceptibility testing. Clin Microbiol Rev 20: 280-322. 
Citation: Abusham AA, Mohammed AH (2016) Evaluation of Helicobacter pylori Eradication Therapy in Dyspeptic Patients in a Teaching Hospital. Int J Clin Pharmacol Pharmacother 1: 104. doi: https://doi.org/10.15344/2456-3501/2016/104

20. Osato MS, Reddy R, Reddy SG, Penland RL, Malaty HM, et al. (2001) Pattern of primary resistance of Helicobacter pylori to metronidazole or clarithromycin in the United States. Arch Intern Med 161: 1217-1220.

21. Bilardi C, Dulbecco P, Zentilin P, Reglioni S, liritano E, et al. (2004) A 10day levofloxacin-based therapy in patients with resistant Helicobacter pylori infection: a controlled trial. Clin Gastroenterol Hepatol 2: 997-1002.

22. Chi $\mathrm{CH}$, Lin $\mathrm{CY}$, Sheu BS, Yang HB, Huang AH, et al. (2003) Quadruple therapy containing amoxicillin and tetracycline is an effective regimen to rescue failed triple therapy by overcoming the antimicrobial resistance of Helicobacter pylori. Aliment Pharmacol Ther 18: 347-353.

23. Liu H, Rahman A, Semino-Mora C, Doi SQ, Dubois A (2008) Specific and sensitive detection of $\mathrm{H}$. pylori in biological specimens by real-time RT-PCR and in situ hybridization. PLoS One 3: e2689.

24. The British National Formulary (BNF) (2012) Ajoint publication of the British Medical Association and the Royal Pharmaceutical Society of Great Britain 63.

25. Chey WD, Wong BC; Practice Parameters Committee of the American College of Gastroenterology (2007) American College of Gastroenterology guideline on the management of Helicobacter pylori infection. Am J Gastroenterol 102: 1808-1825.

26. Calvet X, Sánchez-Delgado J, Montserrat A, Lario S, Ramírez-Lázaro MJ, et al. (2009) Accuracy of diagnostic tests for Helicobacter pylori: a reappraisal. Clin Infect Dis 48: 1385-1391.

27. Gisbert JP, Esteban C, Jimenez I, Moreno-Otero R (2007) 13C-urea breath test during hospitalization for the diagnosis of Helicobacter pylori infection in peptic ulcer bleeding. Helicobacter 12: 231-237.

28. Lind T, Megraud F, Bardhan KD, (1997) The MACH2 study: antimicrobial resistance in Helicobacter pylori therapy: The impact of omeprazole. Gut 41: (suppl1): A89

29. Vaira D, Zullo A, Vakil N, Gatta L, Ricci C, et al. (2007) Sequential therapy versus standard triple-drug therapy for Helicobacter pylori eradication: a randomized trial. Ann Intern Med 146: 556-563.

30. Huang JQ, Wilkinson JM, Chiba N (1997) One-week clarithromyein $500 \mathrm{mg}$ bid is better than 250 bid for eradicating $H$ pylori infection when combined with proton pump inhibitor and metronidazole or amoxicillin: a metaanalysis [Abstract]. Gut 41(suppl1): A90.

31. Fischbach LA, van Zanten S, Dickason J (2004) Meta-analysis: the efficacy, adverse events, and adherence related to first-line anti-Helicobacter pylori quadruple therapies. Aliment Pharmacol Ther 20: 1071-1082.

32. Graham DY, Lew GM, Malaty HM, Evans DG, Evans DJ Jr, et al. (1992) Factors influencing the eradication of Helicobacter pylori with triple therapy. Gastroenterology 102: 493-496. 